\title{
Singularidad de los movimientos migratorios de Cartagena (1988-1999)
}

Juan Alberto Celdrán Iniesta *

\begin{abstract}
RESUMEN
ABSTRACT

La dinámica migratoria del municipio de Cartagena durante el período 19881999 presenta una clara singularidad dentro del comportamiento migratorio regional. Esta especificidad viene definida fundamentalmente por una emigración continua durante estos doce años, que no se ve compensada por los aportes procedentes del exterior municipal. El resultado de ello derivó, obviamente, en un saldo migratorio negativo, que contribuyó a la pérdida de población del municipio. Este hecho resulta tanto más sorprendente cuanto que se ha producido al mismo tiempo que la Región de Murcia pasaba de ser una zona de emigración tradicional a una zona claramente inmigratoria dentro del contexto nacional.

The migratory dynamics of the municipality of Cartagena during the period 1988-1999 shows a clear singularity in the regional migratory behaviour. This peculiarity is esentially defined by a continuous emigration for these twelve years, which is not balanced by the immigration from the outside of the municipality. The result obviously made a negative migratory balance, which contributed to the loss of population. This fact is as much surprising as it has hapenned just at the same time when the Region de Murcia changed its traditional emigratory condition for a clear immigratory condition in the national context.
\end{abstract}

* Licenciado en Geografía e Historia. 


\section{INTRODUCCIÓN}

Desde finales de los años 80 la ciudad de Cartagena sufre una grave crisis en su modelo industrial tradicional, que afecta a sectores básicos de su economía, como la minería metálica, la construcción naval y la industria química. Esta crisis conduce a la ciudad a un grave estancamiento económico y poblacional. Las inversiones realizadas en el inicio de los años 90 para la reactivación económica de la zona mejoran los problemas de desempleo, pero no terminan de culminar en una recuperación demográfica.

Los flujos migratorios de Cartagena entre 1988 y 1999 constituyen un reflejo evidente de la situación social y económica de la ciudad en este período. Los datos demográficos recogidos por el Centro Regional de Estadística de la Comunidad Autónoma de la Región de Murcia (CARM) muestran claramente la relación existente entre el declive económico del municipio y los continuos saldos migratorios negativos a lo largo de los doce años considerados.

Este trabajo pretende mostrar las características generales de estos movimientos migratorios experimentados por Cartagena entre 1988 y 1999, y compararlos con los municipios de su entorno comarcal y con el conjunto de la Región. En primer lugar comentaremos las cifras globales de los movimientos migratorios de los municipios en cuestión. En segundo lugar, desglosaremos estas cifras atendiendo a su carácter intra y extrarregional. Finalmente, expondremos algunas características peculiares de los movimientos migratorios de Cartagena, comparados con los de su entorno comarcal y regional, entre 1995 y 1999, subperíodo para el que existe mayor información publicada.

Recordemos antes de empezar que la Comarca de Cartagena es una entidad meramente geográfica, carente de organización política, y está compuesta por los municipios de Los Alcázares, Cartagena, Fuente Álamo, Mazarrón, San Javier, San Pedro del Pinatar, Torre Pacheco y La Unión. Recordemos también que la Región de Murcia es una Comunidad Autónoma uniprovincial.

La fuente de información utilizada ha sido el Centro Regional de Estadística de la CARM antes mencionado. Este Centro publica series monográficas sobre los movimientos migratorios regionales desde 1988 y de manera notablemente mejorada desde 1996, gracias a la instauración del Registro Continuo de Población a partir del Padrón Municipal de ese año. 
Los datos recogidos para este trabajo se refieren tan sólo a los movimientos migratorios realizados dentro del Estado español. No se recogen movimientos migratorios con el exterior de España. Sin embargo, las cifras de población incluyen población tanto extranjera como nacional (sin discriminarlas) que cambia de residencia dentro de España. Las cifras referidas a la Comarca de Cartagena como conjunto no incluyen las del municipio de Cartagena, salvo que se haga mención expresa en sentido contrario.

\section{DATOS GLOBALES DE LOS MOVIMIENTOS MIGRATORIOS ENTRE 1988-1999}

\subsection{Inmigraciones}

Característica generalizada para toda la Región de Murcia es la oscilación en el ritmo inmigratorio. Tanto Cartagena como su Comarca, la Región y la capital regional repiten los máximos y mínimos inmigratorios en los mismos años (1999 y 1991, respectivamente). (Tabla 1).

El número total de inmigrantes de Cartagena en este período $(25.823$ individuos) supone algo más del $40 \%$ del total comarcal y más del $13 \%$ del total regional. Presenta una tendencia inmigratoria por encima de las 2.000 personas anuales desde 1993.

Tanto la Comarca como la Región muestran una tendencia sostenida al alza inmigratoria desde 1991 (el año 1996 supone una excepción). La Comarca recibió 37.365 inmigrantes y la Región 190.119. La capital regional presenta un ritmo inmigratorio irregular, aunque siempre más elevado que el de Cartagena. Tuvo un total de 44.589 inmigraciones.

\subsection{Emigraciones}

El ritmo emigratorio muestra oscilaciones similares a las de las inmigraciones en toda la Comunidad Autónoma. En 1991 se produce el mínimo emigratorio en toda la Región y el máximo migratorio en 1999, también en toda la Región, excepto en Cartagena, que lo tiene en 1995. La Región sufrió un total de 171.525 emigraciones en el período.

El número total de emigrantes de Cartagena entre 1998 y 1999 asciende a 31.354 individuos (más del $54 \%$ de la Comarca y más del $18 \%$ de la Región). La emigración del municipio de Cartagena incrementa nota- 
Tabla 1. INMIGRACIONES, EMIGRACIONES Y SALDOS TOTALES. 1988-1999

\begin{tabular}{|c|c|c|c|}
\hline \multirow{2}{*}{ Municipio } & \multicolumn{3}{|c|}{ Totales } \\
\hline & Inmigraciones & Emigraciones & Saldo \\
\hline Cartagena & 25823 & 31354 & -5531 \\
\hline \multicolumn{4}{|l|}{ COMARCA DE CARTAGENA } \\
\hline Los Alcázares & 4970 & 2186 & 2784 \\
\hline Fuente Álamo & 1728 & 1451 & 277 \\
\hline Mazarrón & 5504 & 3325 & 2170 \\
\hline San Javier & 10040 & 7648 & 2392 \\
\hline San Pedro del Pinatar & 6667 & 4639 & 2028 \\
\hline Torre Pacheco & 5863 & 4356 & 1507 \\
\hline La Unión & 2593 & 2868 & -275 \\
\hline TOTAL (sin incluir Cartagena) & 37365 & 26473 & 10892 \\
\hline REGIÓN DE MURCIA & 190119 & 171794 & 18325 \\
\hline Murcia capital & 44589 & 42069 & 2520 \\
\hline
\end{tabular}

\begin{tabular}{|c|c|c|c|}
\hline \multirow{2}{*}{ Municipio } & \multicolumn{3}{|c|}{ Migraciones interiores en la Región de Murcia } \\
\hline & Inmigraciones & Emigraciones & Saldo \\
\hline $\begin{array}{l}\text { Cartagena } \\
\text { COMARCA DE CARTAGENA }\end{array}$ & 7395 & 12753 & -5358 \\
\hline Los Alcázares & 2514 & 1320 & 1194 \\
\hline Fuente Álamo & 1084 & 974 & 110 \\
\hline Mazarrón & 2381 & 1642 & 739 \\
\hline San Javier & 4523 & 3562 & 961 \\
\hline San Pedro del Pinatar & 2408 & 2071 & 337 \\
\hline Torre Pacheco & 3479 & 2404 & 1075 \\
\hline La Unión & 1681 & 1976 & -295 \\
\hline TOTAL (sin incluir Cartagena) & 18070 & 13949 & 4121 \\
\hline REGIÓN DE MURCIA & 90108 & 90108 & \\
\hline Murcia capital & 20022 & 21373 & -1351 \\
\hline
\end{tabular}

\begin{tabular}{lccr}
\hline \multirow{2}{*}{ Municipio } & \multicolumn{3}{c}{ Migraciones exteriores a la Región de Murcia } \\
\cline { 2 - 4 } & Inmigraciones & Emigraciones & Saldo \\
\hline Cartagena & 18428 & 18601 & -173 \\
COMARCA DE CARTAGENA & & & \\
Los Alcázares & 2456 & 866 & 1590 \\
Fuente Álamo & 644 & 477 & 167 \\
Mazarrón & 3123 & 1683 & 1440 \\
San Javier & 5517 & 4086 & 1431 \\
San Pedro del Pinatar & 4259 & 2568 & 1691 \\
Torre Pacheco & 2384 & 1952 & 432 \\
La Unión & 912 & 892 & 20 \\
TOTAL (sin incluir Cartagena) & 19295 & 12524 & 6771 \\
REGIÓN DE MURCIA & 100011 & 81686 & 18325 \\
Murcia capital & 24567 & 20696 & 3871 \\
\hline
\end{tabular}


blemente el total comarcal ( 57.827 individuos incluida Cartagena) y sus cifras están mucho más cerca de las de la capital regional (42.069 individuos) que las cifras inmigratorias de ambos municipios, lo cual es muy significativo si se tiene en cuenta la diferencia de población total entre los dos municipios ( 175.011 habitantes de población media de Cartagena en el período frente a 336.580 habitantes de población media de Murcia).

\subsection{Saldos migratorios}

Los saldos migratorios muestran claramente la especificidad migratoria negativa del municipio de Cartagena, ya que éste ofrece un balance de este signo en todos y cada uno de los años del período. El saldo migratorio total para Cartagena es de -5.531 entre 1988 y 1999 , incluyendo tanto los saldos entre municipios de la Región (- 5.358) como los saldos con municipios exteriores a la Región (-173).

Este hecho contrasta fuertemente con el comportamiento de la Comarca, que presenta un saldo positivo en el período (+ 10.892), en especial los municipios costeros. Los únicos municipios de la Comarca que ofrecen saldos negativos en algunos años, no todos, son Fuente Álamo y La Unión, este último debido posiblemente a la crisis irreversible de la minería, su sector económico tradicional y esencial. Cartagena arrastra a su Comarca a tener un saldo negativo en nueve de los doce años del período considerado.

La Región de Murcia ofrece saldos migratorios positivos en todos los años considerados (+ 18.325 en el total). Por su parte, la capital presenta saldos positivos con excepción de los tres últimos años, que se tornan negativos, aunque el saldo final de todo el período es positivo $(+2.520)$.

\subsection{Tasa regional de migración neta}

El estudio de esta tasa para el período 1989-1999 permite comparar la situación migratoria real de los municipios de la CARM, ya que relaciona la población de los mismos con sus saldos migratorios. Las estadísticas regionales se calculan relacionado el saldo migratorio medio de dos años consecutivos y la población a mitad del período considerado.

La Región presenta una tasa media de migración neta en todo el período en torno a 1,44. Todos los municipios de la Comarca de Cartagena superan esta tasa media, excepto Cartagena y La Unión. (Tabla 2). 


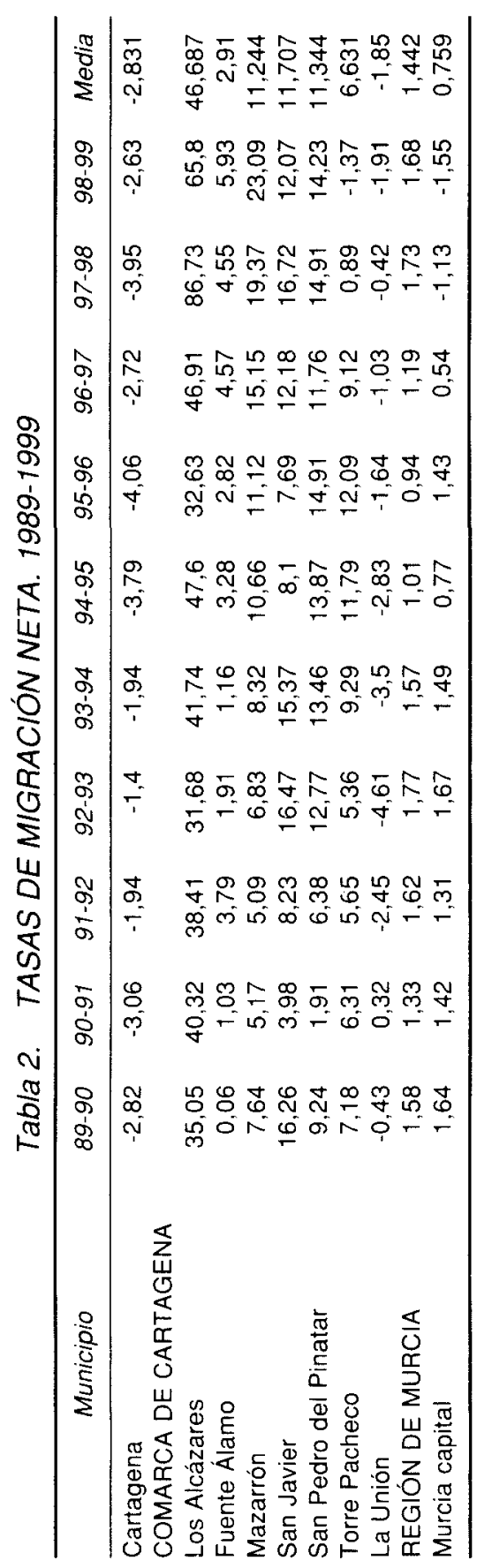


Cartagena presenta una tasa negativa en todos los años entre 1988 y 1999 (- 2,83 de media). En el último intervalo estimado (1998/1999), por ejemplo, ocupa el cuarto lugar por la cola entre los 45 municipios de la Región, con una tasa de - 2,6, sólo superada por los municipios regionales del noroeste.

Esta tasa negativa de Cartagena contrasta vivamente con las de los municipios de su Comarca, especialmente los costeros, que se encuentran entre los diez primeros municipios regionales por tasa de migración neta. De hecho, Los Alcázares es el municipio con la tasa de migración neta más elevada de la Región en todo el período (46,68 de media). En la Comarca, tan sólo La Unión (- 1,85 de media) comparte el signo negativo de Cartagena, pero no de una manera tan exagerada.

El municipio de Murcia presenta tasas positivas débiles hasta 1997/98. A partir de este intervalo se tornan negativas. Su media para todo el período es de 0,75 . Sin embargo, es posible que sus tasas débiles y negativas se expliquen porque parte de su población se dirija a residir a municipios de su periferia. De hecho, Molina de Segura, Alcantarilla, Santomera, Ceutí y Torres de Cotillas presentan tasas de migración neta elevadas.

\section{MOVIMIENTOS MIGRATORIOS INTRA E INTERREGIONALES}

\subsection{Migraciones interiores en la Región de Murcia}

Durante todo este período de 1988-1999 las entradas de población en el municipio de Cartagena son notablemente inferiores a las salidas. En algún año la población de salida llega a doblar a la de entrada y en muchos otros años este hecho también está a punto de producirse. El ritmo emigratorio se incrementa hasta 1990, decae en 1991 y vuelve a incrementarse desde 1992, con una caída en 1996 y nuevo incremento hasta 1999, año que marca el pico del período. El ritmo inmigratorio sigue la misma pauta, con la caída en 1995 y no en 1996. De Cartagena parten hacia otros municipios regionales 12.753 individuos (más del $47 \%$ del total comarcal y más del $14 \%$ del total regional) y a ella llegan 7.395 (más del 29\% del total comarcal y más del $8 \%$ del total regional). Ya se ha mencionado arriba su saldo negativo de -5.358 individuos con otros municipios regionales.

En el resto de la Comarca, tan sólo Fuente Álamo y La Unión muestran una tendencia parecida a la de Cartagena, menos acusada en el caso del primero y más persistente en el segundo caso. Otros municipios, como San Pedro del Pinatar o Torre Pacheco, presentan esporádicamente en algunos años más salidas que entradas. En cifras globales, la Comarca ex- 
perimenta más entradas que salidas de población. De la Comarca parten 13.949 individuos y a ella llegan 18.070 individuos (saldo de +4.121 ). Sin embargo, si se incluyeran las cifras de Cartagena en el cómputo, el saldo comarcal sería negativo.

La capital regional presenta altibajos en el ritmo migratorio, con cuatro años en los que gana población y ocho en los que la pierde. Su saldo final es de -1.351 .

\subsection{Movimientos migratorios con otras Comunidades Autónomas}

\subsubsection{Inmigraciones}

A lo largo del período 1988-1999, las oscilaciones en el ritmo inmigratorio vuelven a ser el rasgo característico regional. Los máximos y los mínimos se producen respectivamente en los siguientes años: para Cartagena, en 1994 y 1991; para su Comarca y la Región, en 1999 y 1991, y para Murcia ciudad, en 1999 y 1988.

En este período 18.428 individuos llegaron a Cartagena procedentes de otras Comunidades Autónomas (más del $48 \%$ del total comarcal y más del $18 \%$ del total regional).

La Comarca presenta desde 1996 un incremento constante de población desde el exterior de la Comunidad Autónoma. Recibió 19.295 individuos en todo el período.

Desde 1996 tanto la Región como su capital experimentan un continuo incremento de inmigración. A la primera llegaron 100.011 individuos en todo el período, en tanto que la segunda recibió 24.567 individuos.

\subsubsection{Emigraciones a otras Comunidades Autónomas}

Al igual que ocurría con las inmigraciones, toda la Región presenta oscilaciones en el ritmo emigratorio. Cartagena presenta su máximo emigratorio en 1995 y su mínimo en 1991. La Comarca de Cartagena, la Región y Murcia capital repiten años de máximos (1999) y de mínimos (1991) y desde 1996 todas ellas experimentan un ritmo emigratorio creciente.

Entre 1988 y 1999, las emigraciones desde Cartagena a otras Comunidades Autónomas ascendieron a 18.601 individuos.

Las cifras totales de emigración para la Comarca alcanzan la cifra de 12.524 individuos. 
En el período considerado salieron 81.686 personas de la Región y de la capital partieron 20.696 personas a residir fuera de la Región.

\subsubsection{Saldos migratorios con otras Comunidades Autónomas}

El saldo migratorio de Cartagena con otras Comunidades Autónomas asciende a - 173 en todo el período. Aun siendo negativo, resulta insignificante si se compara con el saldo que presentaba Cartagena con los municipios regionales (- 5.358). Este hecho constituye la prueba evidente de que en estos doce años el balance migratorio de Cartagena ha favorecido fundamentalmente a municipios de la Región.

El saldo migratorio de la Comarca de Cartagena con otras Comunidades Autónomas es claramente positivo (+6.771). En este caso ni siquiera las cifras negativas de Cartagena harían invertir el signo comarcal si se incluyeran en el cómputo.

La Región de Murcia presenta un carácter claramente receptor en todo el período. Su saldo final es positivo en 18.325 individuos. Este dato muestra la inversión de las pautas migratorias de esta Región, castigada tradicionalmente por la emigración en el pasado y convertida desde los años 80 en foco de atracción poblacional dentro de España.

Murcia capital también presenta un saldo positivo de 3.871 individuos con otras Comunidades Autónomas.

\section{CARACTERISTICAS DE LA POBLACIÓN MIGRANTE EN EL PERÍODO 1995-1999}

El Centro Regional de Estadística proporciona en sus publicaciones información más detallada para este período temporal, referida a características de los migrantes, como su nacionalidad, edad y formación académica, y a otros rasgos como los destinos y procedencias y el origen de los mismos.

\subsection{Nacionalidad}

Entre 1992 y 1999 Cartagena presenta saldos migratorios de individuos nacionales claramente negativos (-3.891), en claro contraste con el resto de la Comarca (+ 4.359) a excepción de La Unión, y con la Región, 
que presenta en todos los años saldos positivos (+ 12.611 en este período), y con la capital $(+1.553)$.

Sin embargo, el saldo migratorio final de individuos extranjeros entre 1992 y 1999 es sorprendentemente positivo para Cartagena $(+172)$, a diferencia de lo que ocurre en la Región (-131) y de la capital (- 624). La Comarca presenta un saldo final positivo $(+52)$ si se incluye a Cartagena en el cómputo. Aunque la contabilización de los inmigrantes extranjeros en el saldo migratorio total no cambia el signo negativo del saldo migratorio total de Cartagena, sorprende esta atracción que el municipio ejerce para los extranjeros en este período de 1992-1999.

\subsection{Destinos y procedencias}

\subsubsection{Migraciones intrarregionales}

En este apartado, Cartagena no presenta un comportamiento diferenciado de su Comarca y de la Región entre 1995 y 1999. Los emigrantes procedentes de Cartagena prefieren como destino preferente el municipio de Murcia (más del $28 \%$ de sus salidas se dirigen allí) y su entorno, pero en términos absolutos, el $54 \%$ de las salidas de Cartagena marcha a residir a otros municipios de su Comarca. Por el contrario, Cartagena no actúa como foco de atracción para los municipios de su Comarca más que en tercer lugar, ya que éstos, intercambian prioritariamente población entre ellos, y en segundo lugar, envían población a la capital regional.

Cartagena tampoco atrae especialmente a población procedente de la Región (aproximadamente sólo el $14 \%$ de los migrantes regionales se dirige a Cartagena) y menos aún de la capital (tan sólo recibe aproximadamente el $8 \%$ de las salidas de ésta). (Tabla 3.1).

\subsubsection{Migraciones interregionales}

En este apartado Cartagena y su Comarca se diferencian de la Región en que reciben sus mayores aportes poblacionales de Andalucía, en lugar de la Comunidad Valenciana, que es la Comunidad Autónoma que ha suministrado tradicionalmente mayor aporte de inmigrantes a la Región de Murcia.

En cuanto a destinos exteriores a la Región, Cartagena se distingue especialmente de toda la Región por enviar mucha más población a Galicia, quizá debido a traslados de población militar entre Departamentos Marítimos de Cartagena y Ferrol. (Tabla 3.2). 


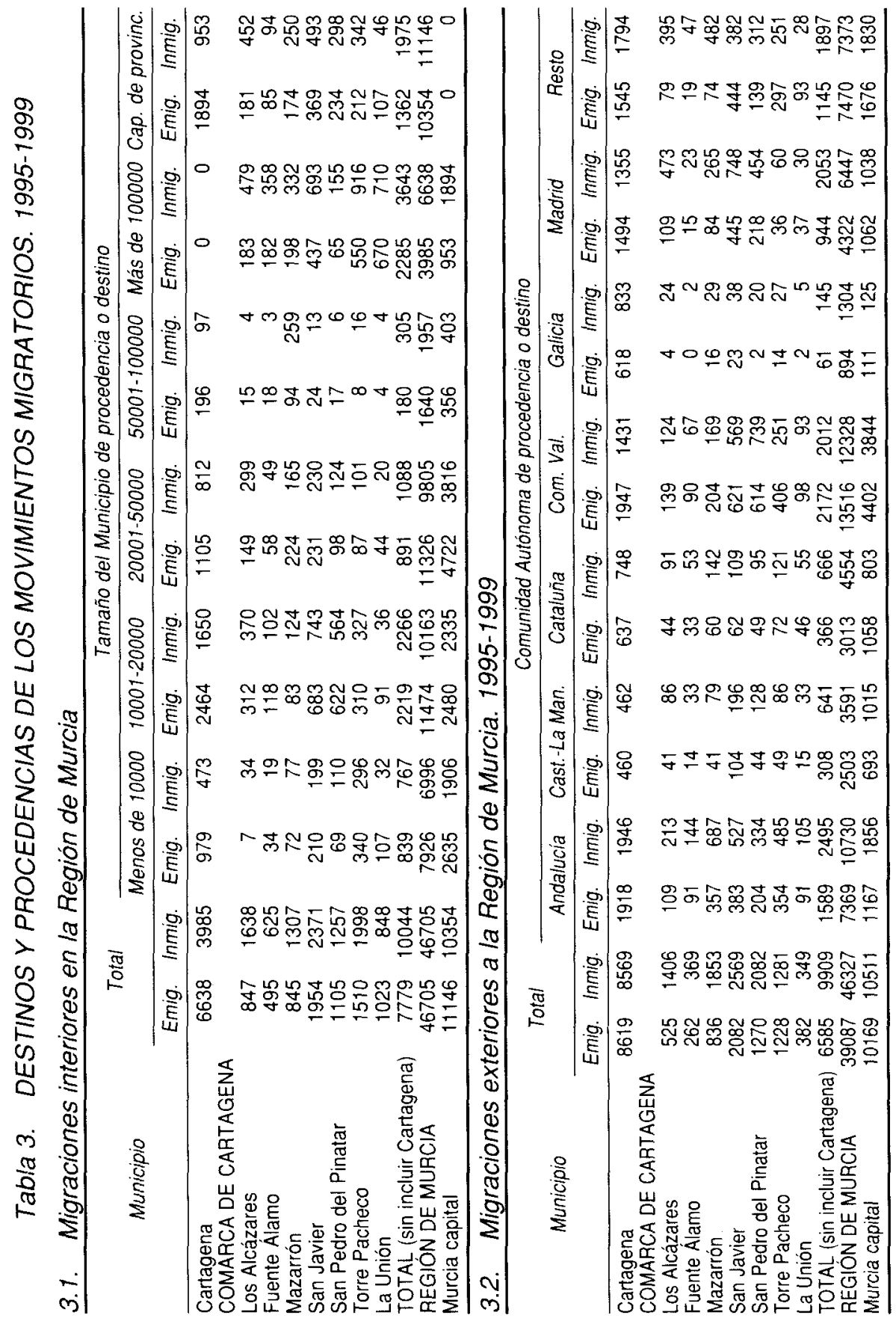




\subsection{Origen de los migrantes}

\subsubsection{Migraciones intrarregionales}

En este período, Cartagena se diferencia de su Comarca y de la Región, aunque no de la capital, en que una gran parte de su población emigrante (más del $56 \%$ ) e inmigrante (más del $40 \%$ ) es nacida en el municipio. Es decir, la población originaria de Cartagena se marcha de y llega a la ciudad en mayor medida que lo hace la población originaria en la Comarca y en la Región.

Otra peculiaridad de Cartagena, a diferencia de su Comarca y de la capital, es que presenta un saldo migratorio claramente negativo de naturales de otras Comunidades Autónomas. (Tabla 4.1).

\subsubsection{Migraciones interregionales}

El comportamiento de Cartagena en este apartado presenta diferencias con respecto a la Comarca y la Región, no así con la capital. La población originaria regional que inmigra a y emigra de Cartagena y Murcia capital es levemente superior en número a la foránea (esto ocurre más claramente en las inmigraciones). Ni en la Comarca de Cartagena ni en la Región sucede esto. Dentro del porcentaje de población regional nativa, tanto en Cartagena como en Murcia ciudad sus poblaciones municipales nativas son mayoritarias a la hora de inmigrar y de emigrar. (Tabla 4.2).

\subsection{Edad de los migrantes}

El Centro Regional de Estadística divide a la población en los siguientes grupos de edad: menos de 16 años, de 16 a 24 años, de 25 a 34 años, de 35 a 44 años, de 45 a 54 años, de 55 a 64 años, de 65 y más.

\subsubsection{Migraciones intrarregionales}

No existen diferencias regionales en lo que se refiere a los grupos de edad más numerosos que inmigran y emigran por la Región. El grupo de edad que más lo hace es el situado entre los 25 y 34 años, seguido del de menores de 16 años y de los situados entre 16 y 24 años. Estos 


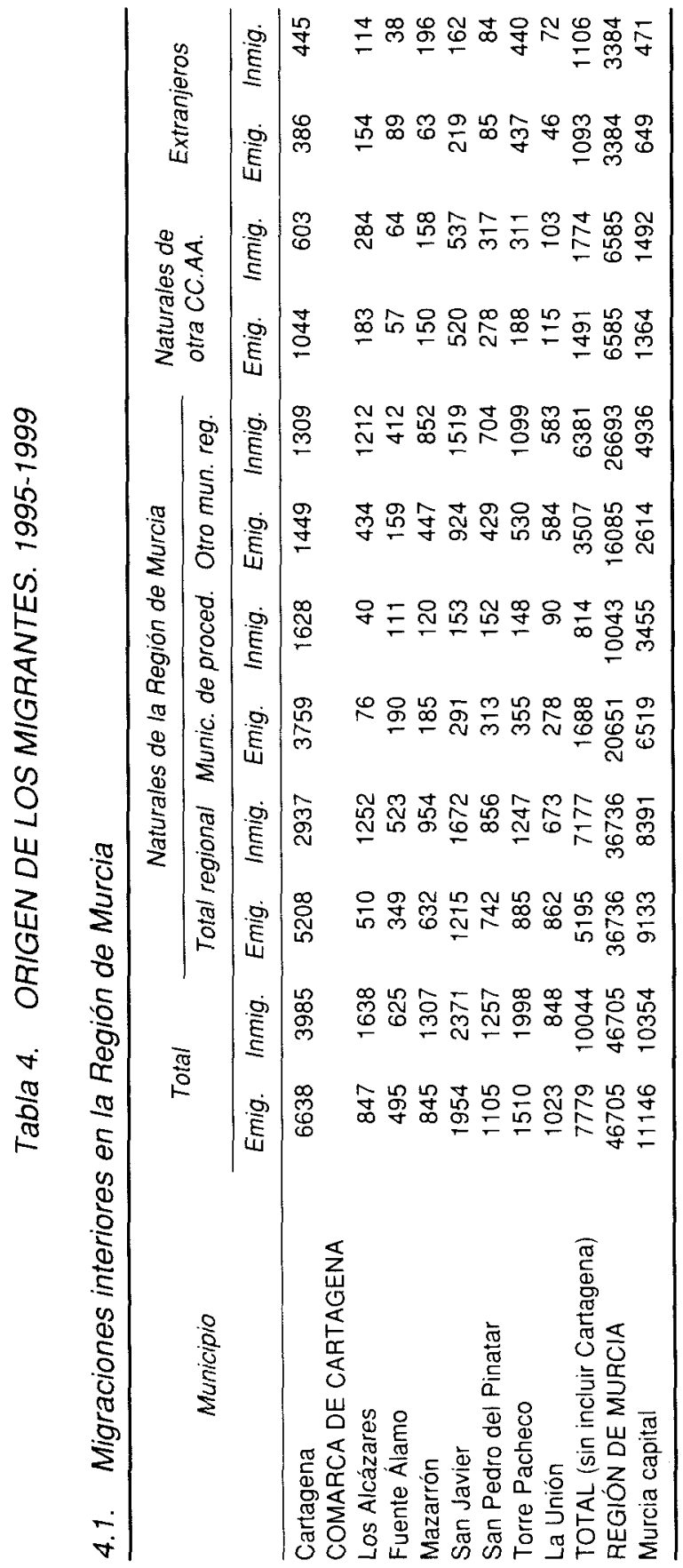




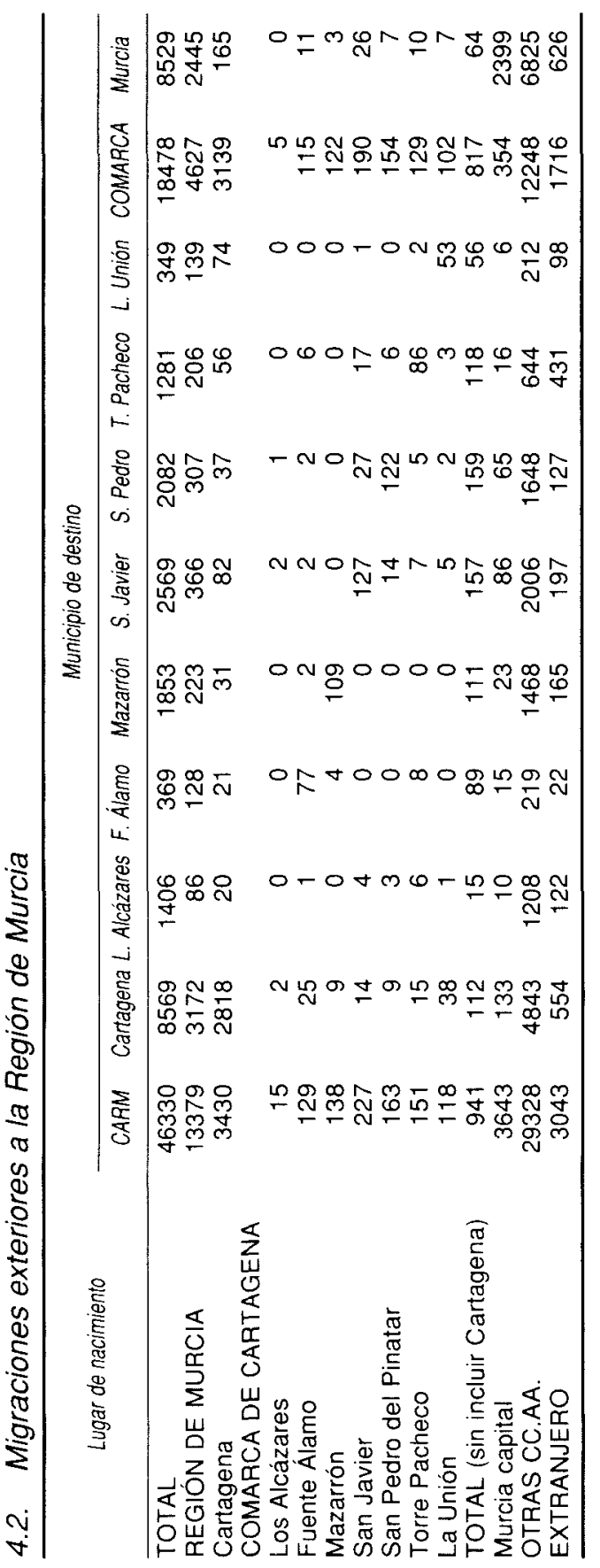

88

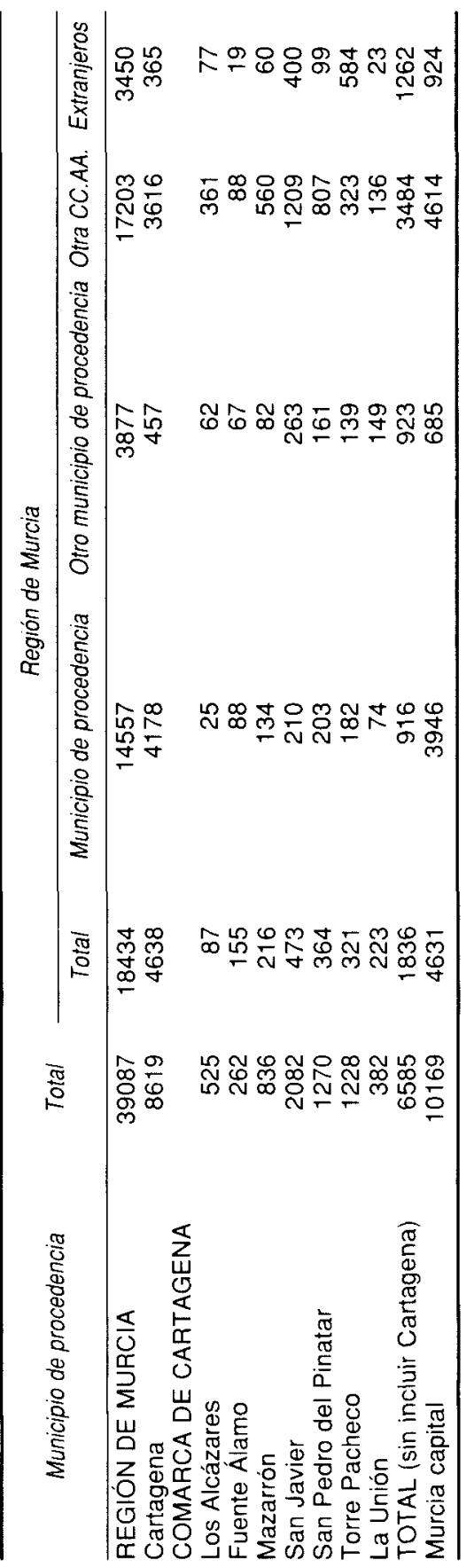

(C) UNED. Espacio, Tiempo y Forma

Serie VI, Geografia, t. 14, 2001 
datos sugieren la existencia de importantes contingentes de población en edad de trabajar que cambian de residencia regional, acompañados de sus familias, posiblemente en busca de los mercados laborales más activos. En este apartado Cartagena se diferencia de la Comarca y de la Región por sus saldos negativos, pero no por las características de los migrantes. (Tabla 5.1).

\subsubsection{Migraciones interregionales}

En este apartado, en lo que a inmigraciones se refiere, Cartagena y su Comarca se diferencian de la Comunidad Autónoma en el segundo grupo de edad predominante: en Cartagena y su Comarca es el de menores de 16 años y en la Región y en la capital es el grupo de 16 a 24 años.

En cuanto a emigración, en toda la Región predomina el mismo grupo de edad: el de 25 a 34 años. Como en el caso anterior, la peculiaridad de Cartagena también se produce en el segundo grupo de edad predominante: menores de 16 años, frente al grupo de 16 a 24 años, segundo en importancia en la Comarca, la Región y la capital. (Tabla 5.2).

\subsection{Nivel académico}

El Centro Regional de Estadística diferencia los siguientes niveles de titulación académica: no sabe leer o escribir, sin estudios, graduado escolar, bachiller y superiores, no clasificables (este grupo aparece sólo para clasificaciones sobre migraciones exteriores a la Región de Murcia). La clasificación publicada por el Centro Regional de Estadística no resulta muy exhaustiva. Convendria haber sabido qué porcentaje del grupo bachiller y superiores tiene título universitario, o haber hecho otro grupo con los universitarios.

\subsubsection{Migraciones intrarregionales}

En lo que se refiere a emigración, el municipio de Cartagena, a diferencia de su Comarca y de la Región, presenta dos peculiaridades negativas: primera, en el grupo de menor nivel recibe más población de la que expulsa y en el grupo más elevado expulsa más población de la que recibe. Segundo, en cifras globales, los contingentes de población más numerosos que emigran pertenecen al nivel académico más elevado (bachiller y superiores). Al mismo tiempo, recibe mayoría de graduados 


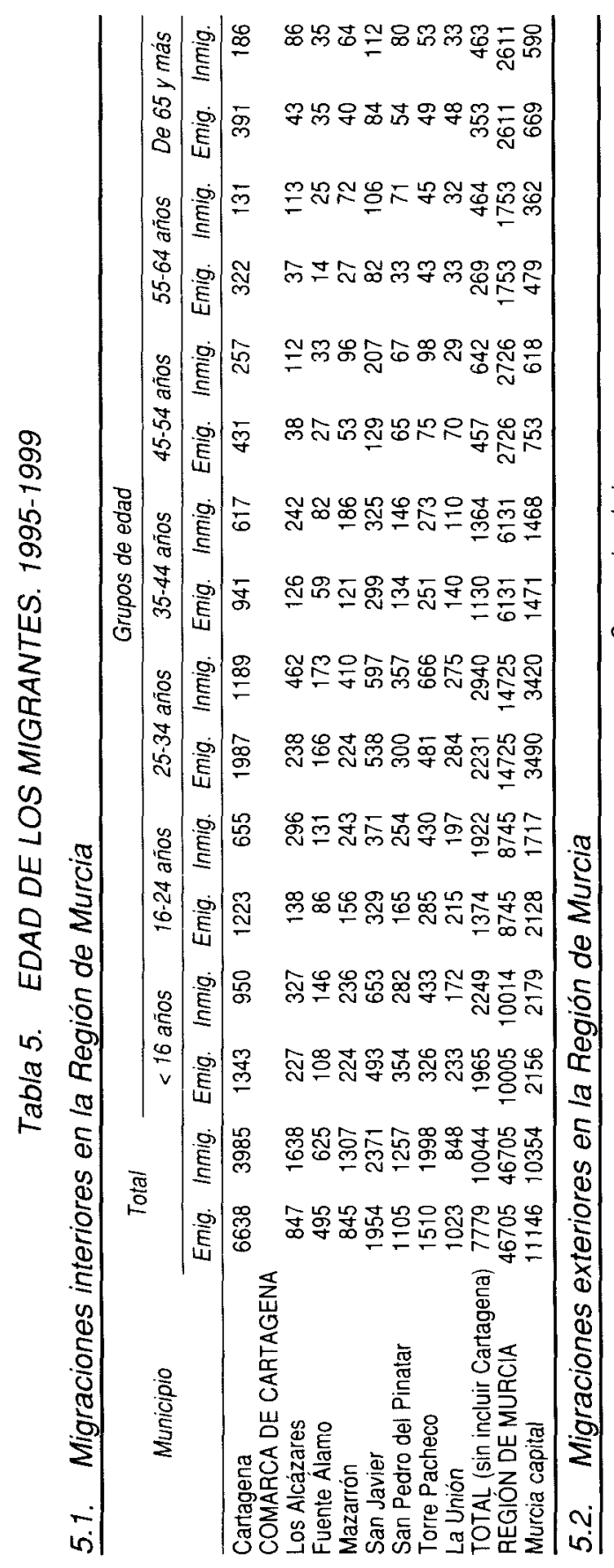

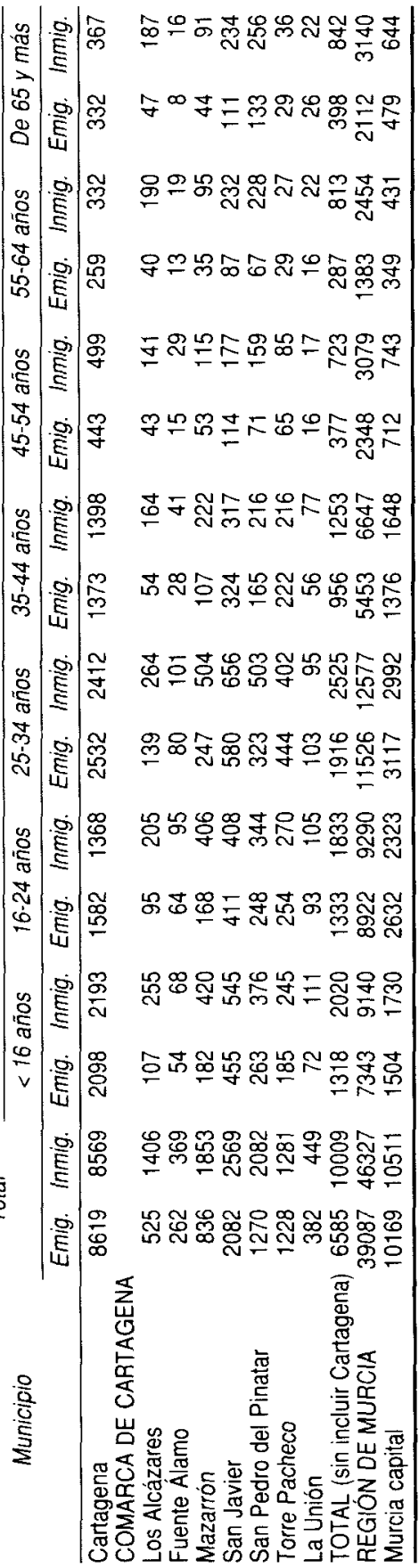

(C) UNED. Espacio, Tiempo y Forma

Serie VI, Geografía, t. 14, 2001 
escolares, con diferencia mínima frente al grupo de bachilleres y superiores. Los dos primeros grupos suponen más de un $36 \%$ de los inmigrantes, porcentaje que se eleva al $68 \%$ si se consideran los tres primeros (en Murcia capital las cifras serían $26 \%$ y $59 \%$, respectivamente).

La Comarca de Cartagena recibe mayoritariamente población del grupo sin estudios. Más del $41 \%$ de sus inmigrantes pertenecen a los dos primeros grupos y más del $77 \%$ a los tres primeros. Cartagena y su Comarca salen perdiendo en el balance migratorio cultural regional. (Tabla 6.1).

\subsubsection{Migraciones interregionales}

En este apartado Cartagena se diferencia sólo de su Comarca. El grupo más numeroso que inmigra del exterior es, como en la Región y la capital, el académicamente más elevado (bachilleres y superiores). Como ocurría en la migraciones internas, en el grupo de menor nivel académico recibe más población de la que expulsa y en el grupo de mayor nivel expulsa más población de la que recibe.

La Comarca de Cartagena recibe mayoritariamente población del grupo sin estudios. Claramente se aprecia un déficit de nivel académico elevado en ia población comarcal inmigrante (sólo entre los dos primeros grupos suman más del $48 \%$ inmigrante).

En el comportamiento emigratorio, Cartagena no presenta diferencias con respecto a la Región y su capital: como en éstas, el grupo que más emigra también es el de bachilleres y superiores. La Comarca de Cartagena se distingue en este aspecto, cuyo grupo emigratorio mayoritario es el de sin estudios. (Tabla 6.2).

\section{CONCLUSIONES}

Durante el período 1988-1999, el municipio de Cartagena experimenta unos movimientos migratorios de signo muy diferente a los del resto de su Comunidad Autónoma, e incluso a los de su entorno más inmediato. Las causas que explican este comportamiento diferenciado exceden de las dimensiones de este trabajo, aunque es obvio que están relacionadas con el deterioro económico que sufre la ciudad desde finales de los años 80 . Esta singularidad en las pautas migratorias pueden sintetizarse en los siguientes rasgos: 


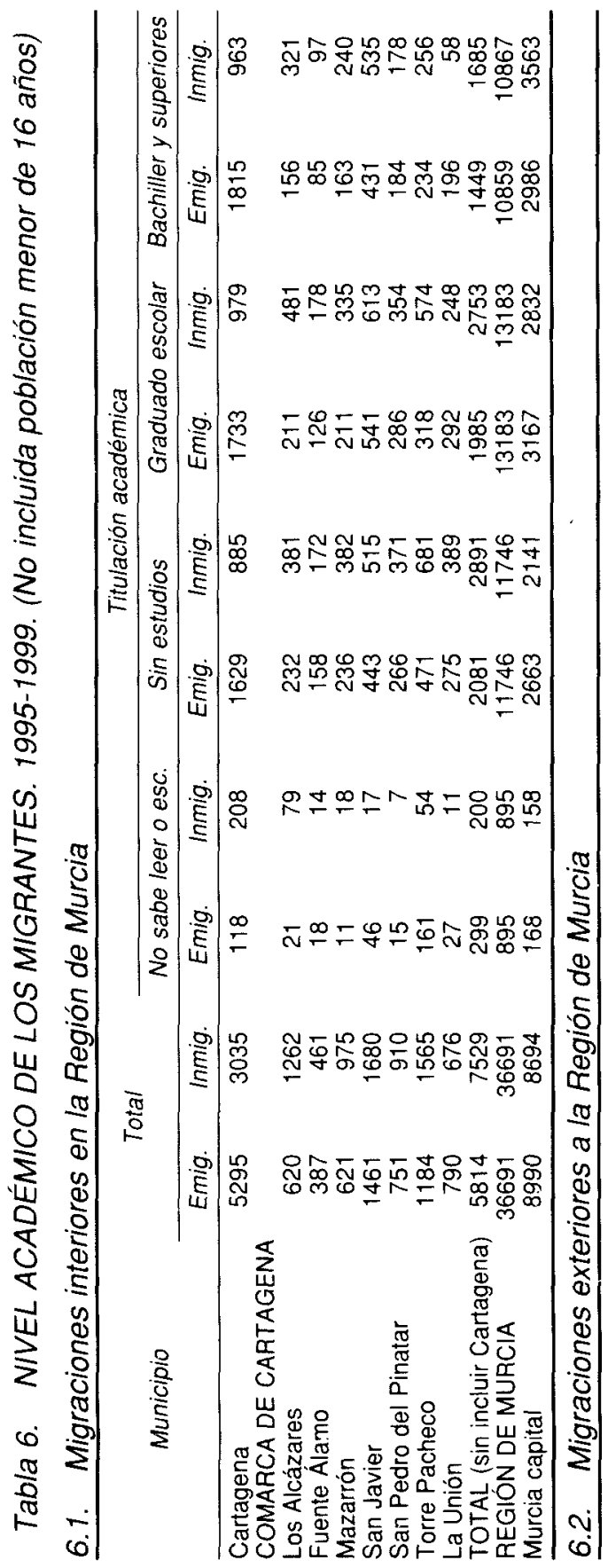

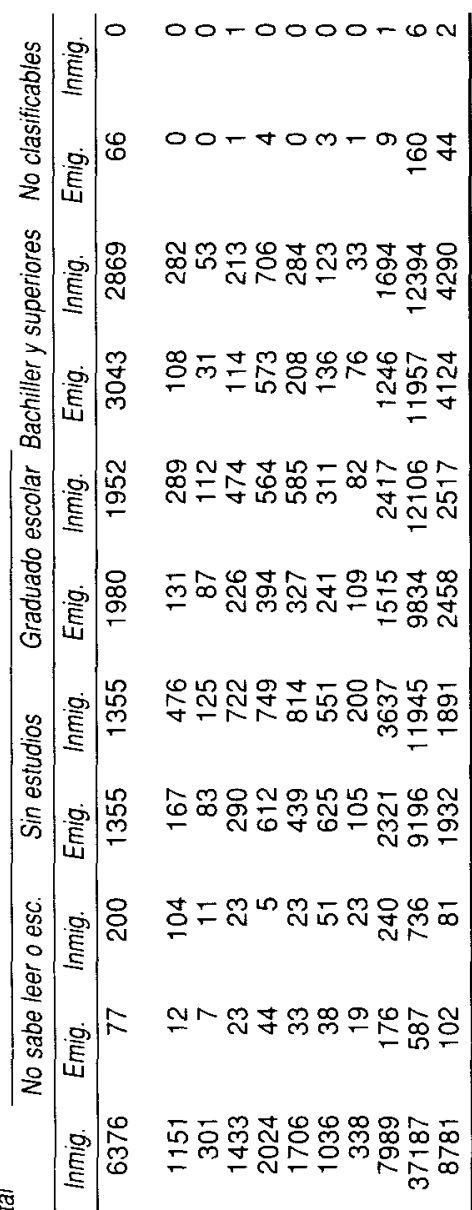

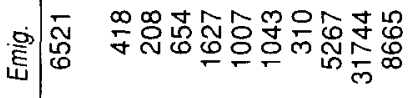

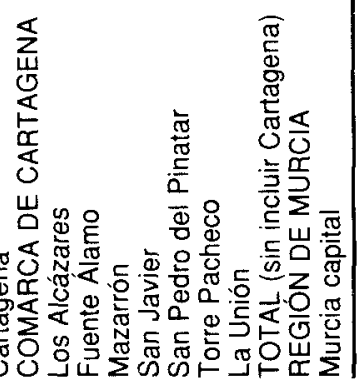


- Entre 1988 y 1999 las cifras de emigración de Cartagena son siempre superiores a las de inmigración, lo cual provoca un importante saldo migratorio negativo. Este saldo negativo contrasta notablemente con los saldos migratorios de su Comarca (a excepción del municipio minero de La Unión y del agrícola de Fuente Álamo) y los de la Región, que se muestran como netamente positivos. El carácter costero del municipio de Cartagena no parece ejercer influencia positiva en su comportamiento migratorio, a diferencia de lo que sucede en los municipios costeros de su Comarca, que presentan una gran vitalidad demográfica.

- En cifras absolutas, la población que emigra de Cartagena se dirige mayoritariamente hacia el exterior de la Región. Sin embargo, la inmigración procedente del exterior regional compensa esta emigración casi en su totalidad. En cambio, la población de Cartagena que marcha a residir a otros municipios regionales no es compensada por inmigración regional, de manera que los saldos migratorios negativos más importantes de Cartagena se producen con otros municipios de la Región de Murcia, especialmente con su capital y con municipios de su propia Comarca. Esta pérdida neta de población por motivos migratorios sólo se repite en un municipio de la Comarca (La Unión), pero no de una manera tan intensa como en Cartagena.

- Durante el período 1995-1999, las emigraciones e inmigraciones intrarregionales de Cartagena siguen las pautas regionales en lo que se refiere a destinos y procedencias. Más de la mitad de sus emigrantes intrarregionales marchan a residir a municipios de la Comarca, en especial a los más dinámicos económicamente. Por otra parte, el municipio de Murcia y su entorno, que constituyen el foco principal de atracción de población regional, captan más del 30\% restante de emigrantes de Cartagena. Sin embargo, lo verdaderamente peculiar es que Cartagena pierde población, en los saldos migratorios recíprocos, no sólo con el municipio de Murcia, sino con todos los municipios de su Comarca. Aun siendo el municipio mayor de su Comarca, no se comporta como polo de atracción poblacional para municipios cercanos más pequeños, sino como foco de repulsión hacia ellos.

Con respecto a los destinos exteriores a la Región de Murcia, entre 1995 y 1999 Cartagena presenta un comportamiento migratorio diferenciado con relación a Galicia y algo diferenciado con respecto a Andalucía, quizá por sus relaciones militares con las bases navales de estas dos Comunidades Autónomas.

- En lo que se refiere a la relación entre migraciones y origen de la población migrante, tanto en los movimientos migratorios interiores como 
en los exteriores a la Región, la población nativa municipal marcha de y regresa a Cartagena en el período 1995-1999 en mayor medida de lo que lo hace la población nativa de la Comarca y la Región en sus respectivos municipios.

- Entre 1995 y 1999, en cuanto a grupos de edad, la única diferencia significativa de Cartagena con el resto de la Región, se encuentra en la mayor importancia del grupo de edad de menores de 16 años, que emigra de e inmigra a Cartagena en mayor medida que en el resto de la Región, lo que presupone la existencia de un mayor peso de la migración familiar en Cartagena que en el resto de la Región.

- Entre 1995 y 1999, en el balance académico de la población migrante, Cartagena presenta un saldo general bastante negativo, más en sus intercambios con el resto de municipios regionales que con el exterior de la Región. En este aspecto, esta negatividad es compartida por su Comarca.

\section{BIBLIOGRAFIA}

Centro Regional de Estadística (Consejeria de Economia y Hacienda de la Región de MurCIA). Movimientos migratorios de la Región de Murcia. Años 1995, 1996, 1997, 1998, 1999. Murcia.

- Padrón Municipal de habitantes de la Región de Murcia 2000. Murcia. 2002. 